\title{
ЭКОЛОГИЧЕСКАЯ ОЦЕНКА РЕКИ ПСЁЛ (В ПРЕДЕЛАХ КУРСКОЙ ОБЛАСТИ) ПО КОМПЛЕКСУ ГИДРОЛОГИЧЕСКИХ ПОКАЗАТЕЛЕЙ
}

\section{ENVIRONMENTAL ASSESSMENT \\ OF THE PSEL RIVER (WITHIN \\ THE KURSK REGION) BY A COMPLEX OF HYDROLOGICAL INDICATORS}

\section{E. Dmitrieva}

Summary. In the course of our own research, we can conclude that the deterioration of the hydrological regime of the Psel river can lead to an extremely difficult and unstable ecological situation both of the river itself and its valley. The main problems of deterioration of the hydrological regime of the PSL can be attributed to a drop in the water level and a decrease in the flow rate in the river, which will lead to the following consequences: rapid overgrowth of aquatic vegetation, lowering the water level in tributaries of the PSL, floodplain and riverine swamps, lakes, which causes a sharp decrease in the area of open mirrors of the Ples and, accordingly, a decrease in almost all groups of birds of the water, wetland and water-coastal complex.

Keywords: ecological assessment, river Psel, hydrological indicators, anthropogenic activity, hydrological regime, ecological situation.

\author{
Дмитриева Екатерина Леонидовна \\ К.б.н., дочент, Курский государственный \\ университет \\ sv-dmitr@yandex.ru
}

Аннотация. Ухудшение гидрологического режима реки Пеёл может привести к крайне тяжелой и нестабильной экологической обстановке как самой реки, так и ее долины. Косновным проблемам ухудшения гидрологического режима Псла можно отнести падение уровня воды и уменьшение скорости течения в реке, которые приведут к следующим последствиям: быстрому зарастанию водной растительностью, что вызовет ухудшение кислородного режима (вплоть до заморов рыбы) и изменение видового состава численности рыб реофильной группы; понижению уровня воды в притоках Псла, пойменных и прирусловых болотах, озерах, что приведет к резкому уменьшению площадей отрытых зеркал плесов и соответственно уменьшению практически всех групп птиц водного, водно-болотного и водно-берегового комплекса.

Ключевые слова: экологическая оценка, река Пёл, гидрологические показатели, антропогенная деятельность, гидрологический режим, экологическая обстановка.

Общая площадь бассейна - 22,8 тыс. км2. В пределах области Псёл имеет длину около 170 км, с площадью бассейна около 5 тыс. км2. Исток реки Псёл расположен в Российской Федерации на границе Белгородской и Курской областей около села Пригорки, которое расположено в Прохоровском районе Белгородской области. Через территорию Украины река протекает, пересекая Сумскую и Полтавскую область по Приднепровской низменности. Псёл втекает в Днепродзержинское водохранилище [1]. Долина реки пересекается многочисленными старицами, а в низовьях река течет по заболоченной равнине.

Псёл принимает значительное количество, как левых, так и правых притоков. Наиболее крупными из левых притоков являются речки Солотина, Ивня, Пена, Бобравка, Илек, а из правых - Запселец, Суджа, Воробжа. В местахблизкогоподходаПсла кОбоянской водораздельной гряде (в Обоянском и Беловском районах) в Псел впадает значительное количество небольших правобережных притоков, «разрезающих» водораздельную гряду - Трубеж, Усланку, Туровку, Каменку, Рыбинку, Долгий, Корочку, Беличку, Конопельку, Смердицу. Эти притоки, несмотря на незначительную площадь водосбора, оказывают 


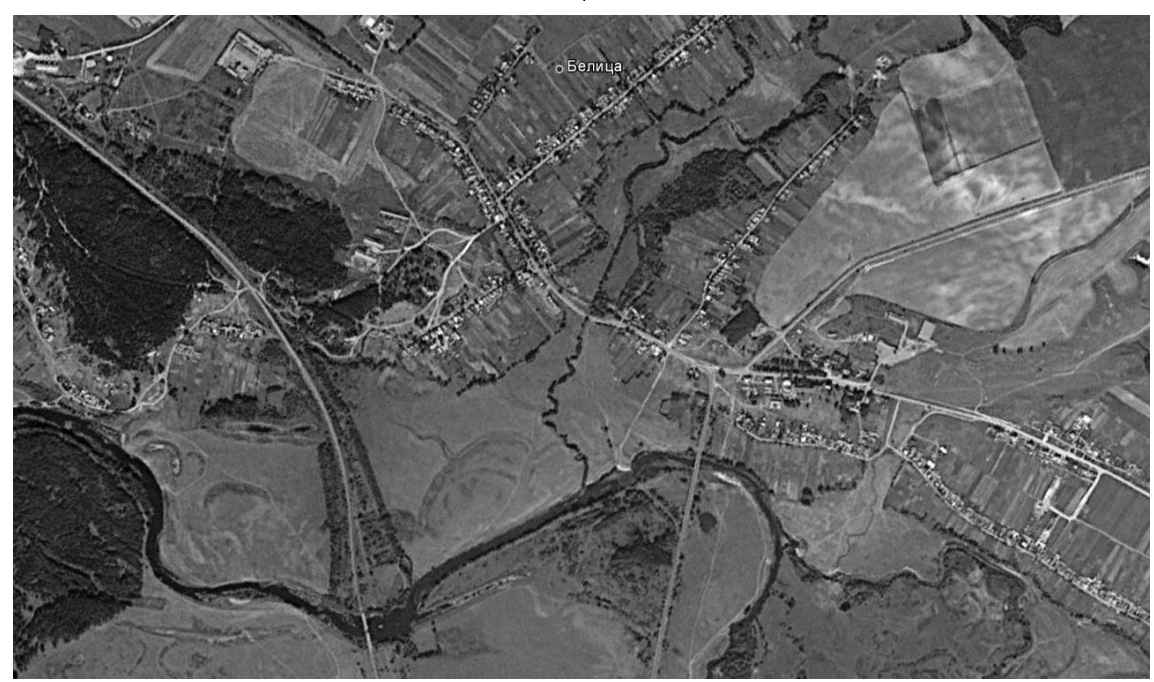

Рис. 1. Створ № 1 (космоснимок, место створа обозначено красной точкой)

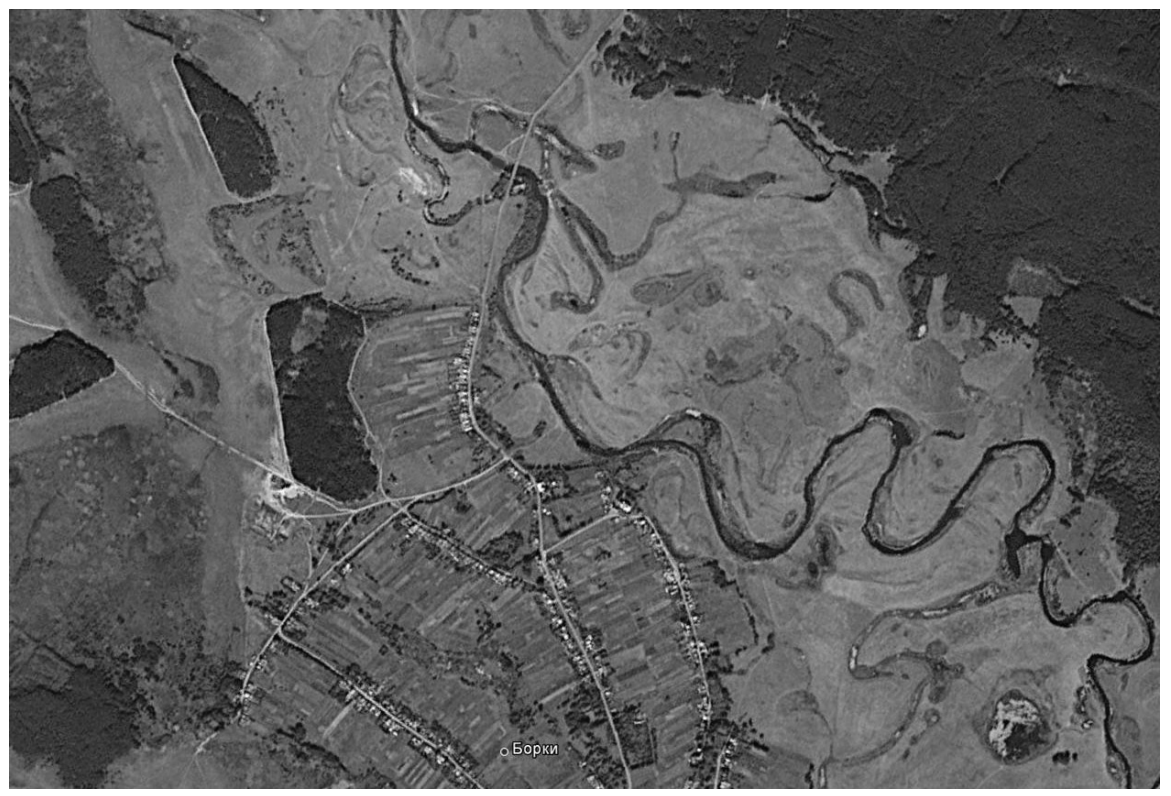

Рис. 2. Створ № 2 (космоснимок, место створа обозначено красной точкой)

большое значение на Псел из-за относительно большого падения (до 0,5 м/км), протекания по территориям с высокой густотой эрозионного расчленения (около 1,5 км/ км2) и максимальной его глубиной (от 80 до 100 м). Максимальной по области также является и плотность оврагов (до 4 овражных вершин/км2). Важным фактором является южная экспозиция Обоянской водораздельной гряды и ее значительная остепненность. Поэтому при оптимальной совокупности нескольких факторов (высоты снегового покрова, «дружной» весны, с солнечным дневным временем суток) разлив на реке Псёл начинается значительно быстрее, чем на других реках области, вода в течение нескольких дней доходит до максимальных отметок, но также быстро и спадает. Немалую роль В этом играют именно небольшие притоки правобережья, текущие с Обоянской водораздельной гряды.

Для проведения исследований по определению гидрологического состояния реки Псёл нами на участке от с. Песчаное до с. Гуево были выбраны три створа. Первый створ - 300 метров ниже по течению автодорожного моста через Псел между с. Белица и Гирьи (Беловский р-н). Второй - 100 метров ниже по течению автодорожного моста через Псёл между с. Уланок и с. Борки (Суд- 
Таблица 1. Гидрологическая характеристика реки Псёл

\begin{tabular}{|c|c|c|c|c|c|c|c|c|c|}
\hline & \multicolumn{3}{|c|}{ с. Белица } & \multicolumn{3}{|c|}{ с. Борки } & \multicolumn{3}{|c|}{ с. Плехово } \\
\hline & 1 & 2 & 3 & 1 & 2 & 3 & 1 & 2 & 3 \\
\hline 1. Ширина русла (м) & 43 & 40 & 42 & 26 & 26 & 26 & 31 & 30 & 31 \\
\hline \multicolumn{10}{|l|}{ 2. Глубина (м) } \\
\hline а) максимальная & 1,76 & 1,4 & 1,7 & 3,12 & 2,72 & 3,0 & 2,64 & 2,4 & 2,55 \\
\hline 6) минимальная & 0,1 & 0,02 & 0,07 & 1,2 & 1,0 & 1,17 & 1,82 & 1,75 & 1,8 \\
\hline в) средняя & 1,18 & 0,82 & 1,06 & 2,12 & 1,78 & 2,05 & 2,08 & 1,82 & 2,0 \\
\hline \multicolumn{10}{|c|}{ 3. Скорость течения (м/с) } \\
\hline а) максимальная & 0,28 & 0,31 & 0,43 & 0,32 & 0,34 & 0,37 & 0,27 & 0,30 & 0,33 \\
\hline 6) минимальная & 0,0 & 0,0 & 0,0 & 0,0 & 0,0 & 0,08 & 0,26 & 0,26 & 0,28 \\
\hline в) средняя & 0,18 & 0,19 & 0,22 & 0,16 & 0,18 & 0,19 & 0,30 & 0,30 & 0,32 \\
\hline
\end{tabular}

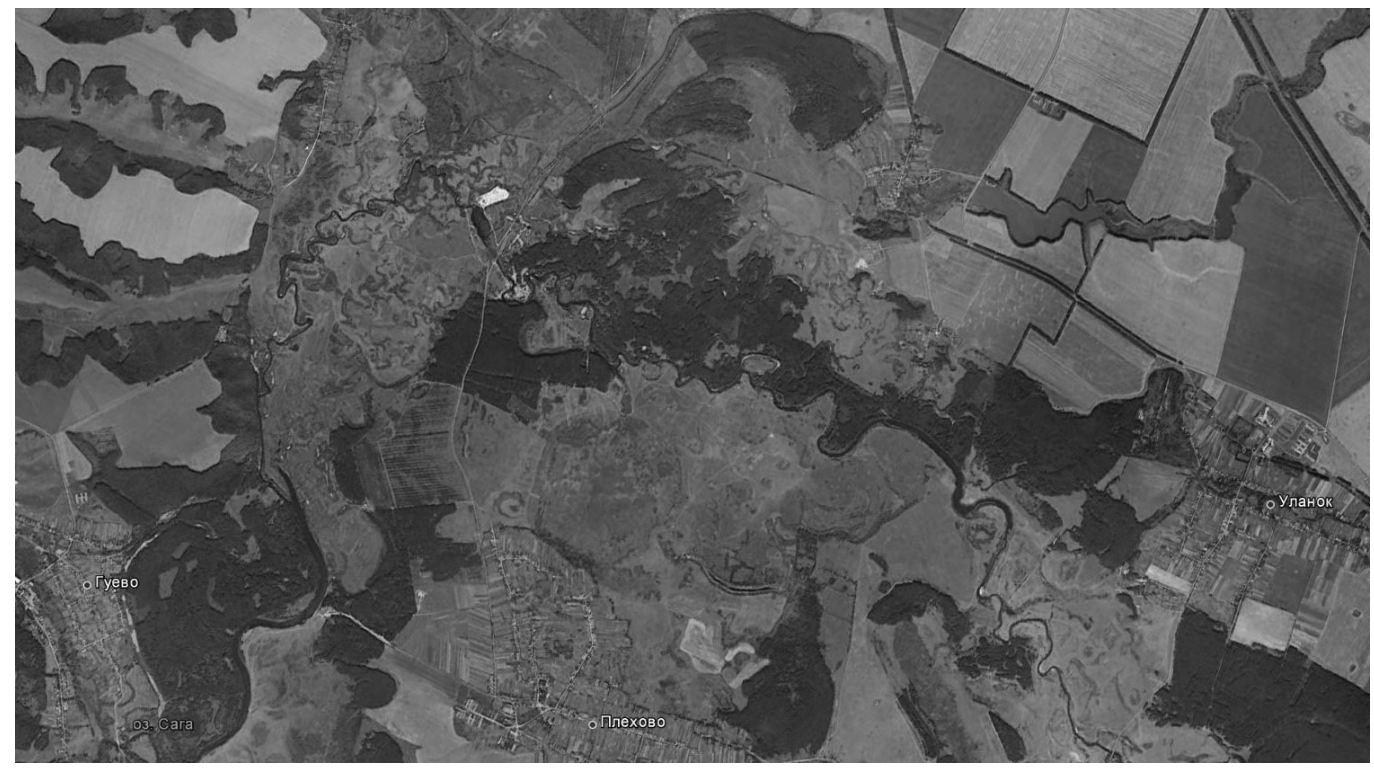

Рис. 3. Створ № 3 (космоснимок, место створа обозначено красной точкой)

жанский район) и третий - 100 метров ниже по течению автодорожного моста через Псёл между с. Плехово и г. Суджа (Суджанский район).

Створ № 1 (географические координаты: $51^{\circ}$ 06>42,8» северной широты $35^{\circ}$ 33,25,7» восточной долготы): мелководный перекат, зарастающий в летний период. Основное течение проходит под левым берегом по фарватеру узкой струей. Имеется мертвая зона под правым берегом на мелководье. Береговая линия пологая, дно песчаное (рис. 1).

Створ № 2 (географические координаты: $51^{\circ}$ 06'54,5" северной широты $35^{\circ} 23^{\prime} 59,2 »$ восточной долготы): типичный участок русла реки Псёл. Основная струя проходит от середины к левому берегу, ближе к правому берегу над максимальной глубиной имеется обратное течение и далее - мертвая зона. Береговая линия обрывистая, дно глинистое (рис. 2).
Створ № 3 (географические координаты: $51^{\circ}$ 07'55,3" северной широты $35^{\circ}$ 17'56,2» восточной долготы): участок русла в поперечном разрезе близок к прямоугольнику, глубина начинается практически сразу от береговой линии, с максимальной амплитудой не более 0,8 метра. Скорость течения на поверхности практически одинакова по всей ширине створа. Береговая линия обрывистая, дно глинисто-песчаное, по всей ширине заросшее до поверхности воды стрелолистом в летний период (рис. 3).

Замеры проводились в июле (во второй и третье декаде), во второй декаде октября и первой декаде ноября. Замеры на всех створах делались в течение одного светового дня. В связи с выпадением ливневых грозовых дождей во второй половине июля и колебаниями уровня воды, замеры проводились трижды, после чего были выведены средние показатели. В осенний период выпадение осадков было незначительным, поэтому прово- 
дились замеры одноразовые. Для проведения замеров выбирались дни с минимальной скоростью ветра (штилевые).

Ширина реки определялась с помощью маркированного троса, глубина выверялась глубомером через каждые 2 метра. Скорость течения на поверхности определялась с помощью поплавка, погруженного в вертикально в воду на 8/10 своего объема. Точки замера скорости течения соответствовали точкам промера глубин. В каждой точке проводилось по три замера, для фиксирования времени проплыва использовался стандартный секундомер [2]. Итоговое время определялось по усредненному показателю. Результаты исследований отражены в таблице 1.

Выбранные створы в целом соответствовали средним показателям русла Псла на данном участке. От с. Песчаное до с. Гуево русло реки имеет среднюю ширину до 35-40 метров. В ряде случаев наблюдаются расширения до 60-70 метров. Колебания глубин, чередования плесовых участков и перекатов имеют широкую вариативность.

Относительно широкий и глубокий плесовый участок от ж/д моста у с. Белица до х. Сосновый бор (средняя ширина 50-55 метров, глубина от 3 до 5 метров) протяженностью около 2 км сменяется на относительно узкий и мелководный участок (ширина до 40 метров, глубина 1,5-2,5) идущий до с. Спальное. Под с. Спальное расположен мелководный перекат, после чего до с. Борки идет сильно меандрированное русло стандартной шириной от 25 до 30 метров, с глубинами по фарватеру 2-2,5, но с ямными участками на поворотах до 7-9 метров. Под с. Борки снова река образует мелководный перекат, после чего русло приобретает стандартные параметры. Через 1,5 км русло резко расширяется до 100-120 метров и глубинами 4-6 метров. Примерно через 2 км русло реки снова переходит в стандартные размеры и так протекает почти до с. Гуево. Перед Гуево наблюдается резкое расширение Псла до 80-100 метров и увеличение глубин по фарватеру, что возможно было связано и с долгим функционирование водяной мельницы и плотины под с. Гуево.

Так же имеются и другие следы человеческой деятельности. Ниже моста между с. Плехово и г. Суджа образован котлован в результате работы земнснаряда в 2002 году. Вымытая котловина доходила до 150-200 метров в диаметре и достигала более 12 метров в глубину. Также было частично до 2006 года зарегулировано русло Псла у с. Крупец (остатки плотины смыло в половодье 2006 года, замыв при этом зимовальную яму глубиной до 7 метров). В 2007 году было начато строительство переливной плотины у с. Уланок, которое осталось до кон- ца незавершенным, но в какой-то степени выполняющее функцию подпора.

Необходимо отметить, что общий уровень и расход воды на реке Псёл стал неуклонно снижаться за последние годы.

По данным гидрологического поста у г. Обоянь средний годовой расход воды за последние 5 лет был около 3,8 м3/с, что ниже среднестатистического (4,1 м3/с). Например, средний годовой расход воды доходил до 5,5 м3/с, с 1991 по 1995 до 4,3 м3/с, с 1995 до 2005 года составил около $4,2 \mathrm{m3} / \mathrm{c}$.

Аналогично и падение уровня воды, особенно заметное в меженный период. Если среднегодовой уровень за последние 5 лет понизился до 25 см, то уровни в период меженей до 52 см.

Аналогичная ситуация наблюдается и на всех притоках Псла, часть из которых стала полностью пересыхать в летний период (р. Бобравка, р. Гирьяной, р. Беличка и др.).

Некоторый подъем уровня воды при уменьшении расхода в летнее время обусловлен интенсивным зарастанием русла водной растительностью, в какой-то степени выполняющей роль подпорных плотин. Зарастание русла Псла до 80-90\% отмечено повсеместно, кроме плесовых участков и отдельных ямных с глубинами более 4,5-5 метров за счет захватывания стрелолистом.

Колебания уровня воды часто связаны не с количеством выпадающих осадков, а антропогенным влиянием, особенно в осенний период. Это обусловлено наличием на притоках Псла большого количества прудов, особенно на правобережьи. Так, на системе притоков Трубеж, Усланка, Туровка, Каменка, Рыбинка, Стригосла, Долгий, Корочка, Беличка, Воробжа расположено более 50 прудов. Мощные прудовые системы созданы и на левобережных притоках Псла (Пенке, Бобравке, Ильке). Большая часть данных прудов сегодня находятся в различной форме собственности, при этом наблюдается постоянный сброс воды с большинства из них в осенний период.

Количество осадков, выпадающее на площади водосбора Псла также имеет общие тенденции к уменьшению до $35-40 \%$.

К основным причинам, взывающим ухудшение гидрологического режима рек из-за недостаточного питания можно отнести:

а) естественные - наступление межвековой тепло-засушливой климатической фазы, прогнозируемой еще в середине 80-х годов 20-го века с пред- 
полагаемым пиком в 2018-2020 годах; спрямление русла реки за счет образовавшихся меандров, особенно интенсивно в районе сел Песчаное, Гирьи, Белица, Спальное;

б) антропогенные - полное прекращение лесомелиоративных мероприятий, уход от травопольной системы земледелия и переход на «рыночные» культуры - сахарную свеклу, кукурузу, подсолнечник (пропашные), а также сою. Все эти культуры яровые, с поздней вегетацией, что приводит кроме влагопотерь из-за осенней вспашки и отсутствии травяного покрова в поздне-осенний и зимний периоды, мощной влагопотери в период апреля и начала-середины мая из-за поздней вегетации. Пахотные пространства, не имеющие защиты от температуры и весенних суховеев, почти полностью теряют почвенную влагу. Выпадающие в период второй половины июня-начала июля осадки не в состоянии насытить почву, что предотвращает проникновение воды в питающие реки горизонты. Вместо летних паводков, типичных ранее для начала-середины июля наступает непрекращающаяся межень, идущая от середины апреля до конца августа, иногда до конца сентября.

По имеющимся данным, полученным в ходе проведения собственных исследований и данным дистанционного зондирования, практически все посевные площади представлены посевами яровых культур.

Переход большей части прудовых хозяйств в частные руки обуславливает полную нестабильность годового стока в связи с постоянными экономическими и юридическими проблемами у собственников.

«Наложение» естественных климатических факторов на условия, вызванные нестабильной социально-экономической обстановкой, особенно из-за ориентировки мелких фермерских хозяйств на спросы «рынка», привели к крайне тяжелой и нестабильной экологической обстановке как самого Псла, так и его долины.

Основные проблемы ухудшения гидрологического режима Псла связаны с падением уровня воды и уменьшением скорости течения (и расхода воды) в Псле которые приводят:

- к быстрому зарастанию водной растительностью, что вызывает ухудшение кислородного режима (вплоть до заморов рыбы); постоянному накоплению илов в русле, что еще усиливает зарастание и обмеление реки; ухудшению кислородного режима;

- к изменениям видового состава и численности рыб реофильной группы: жерех, елец, голавль, судак, численность которых интенсивно падает;
- к понижению уровня воды в притоках Псла, пойменных и прирусловых болотах, озерах, что вызывает резкое уменьшение площадей отрытых зеркал плесов и соответственно уменьшению практически всех групп птиц водного, водно-болотного и водно-берегового комплекса, в первую очередь уток, чаек, пастушковых (лысуха, камышница), за исключением птиц, гнездящихся на зарослях водной растительности (камышовок);

- к наличию больших площадей высохших пойм, заросших осоками, что провоцирует местное население к постоянному пусканию палов, как в весенний (гнездовой), так и в поздне-летний периоды как по самим поймам, так и при сжигании стерни, после чего палы переходят на пойму.

Отсутствие половодья и общее падение уровня воды в Псле и притоках, а также дальнейшее обсыхание поймы еще более усиливает тенденции к ее освоению:

1. под растениеводство и выпас скота;

2. под различные типы застроек (без согласования с органами местного самоуправления), в том числе в водоохранной зоне и прибрежной полосе;

3. под создание подпоров местным населением, не имеющих экологических проектов, не предусмотренных никакими планами и несущих постоянную угрозу срыва и резкого падения уровня воды;

4. для быстрого и массового истребления водных биоресурсов, особенно в зимний период самыми варварскими способами (глушение взрывчатыми веществами, использование электрического тока, химических веществ, битье острогой, стрельба из ружья щук в период нереста, более редким является багрение в зимний период);

5. для массового подъезда к реке на автотранспорте и их мытья, данная тенденция процветает повсеместно. Массовый прессинг приводит к тому, что берега реки почти на всем протяжении представляют собой одну большую свалку пластика, битого стекла и другого бытового мусора. Неоднократно отмечались факты завоза и сброса на берега и в русло реки мешков с мусором.

Кроме того, повсеместно отмечена тенденция использования различных плавсредств с подвесными моторами, в том числе катеров и гидроциклов, которые подвозятся на автомобилях с прицепами, что с учетом ширины русла и возможности разрушения береговой линии недопустимо.

Также отмечено большое количество пищевых отбросов, что привлекает постоянно бродячих кошек, собак, врановых птиц. Обычными постройками на бере- 


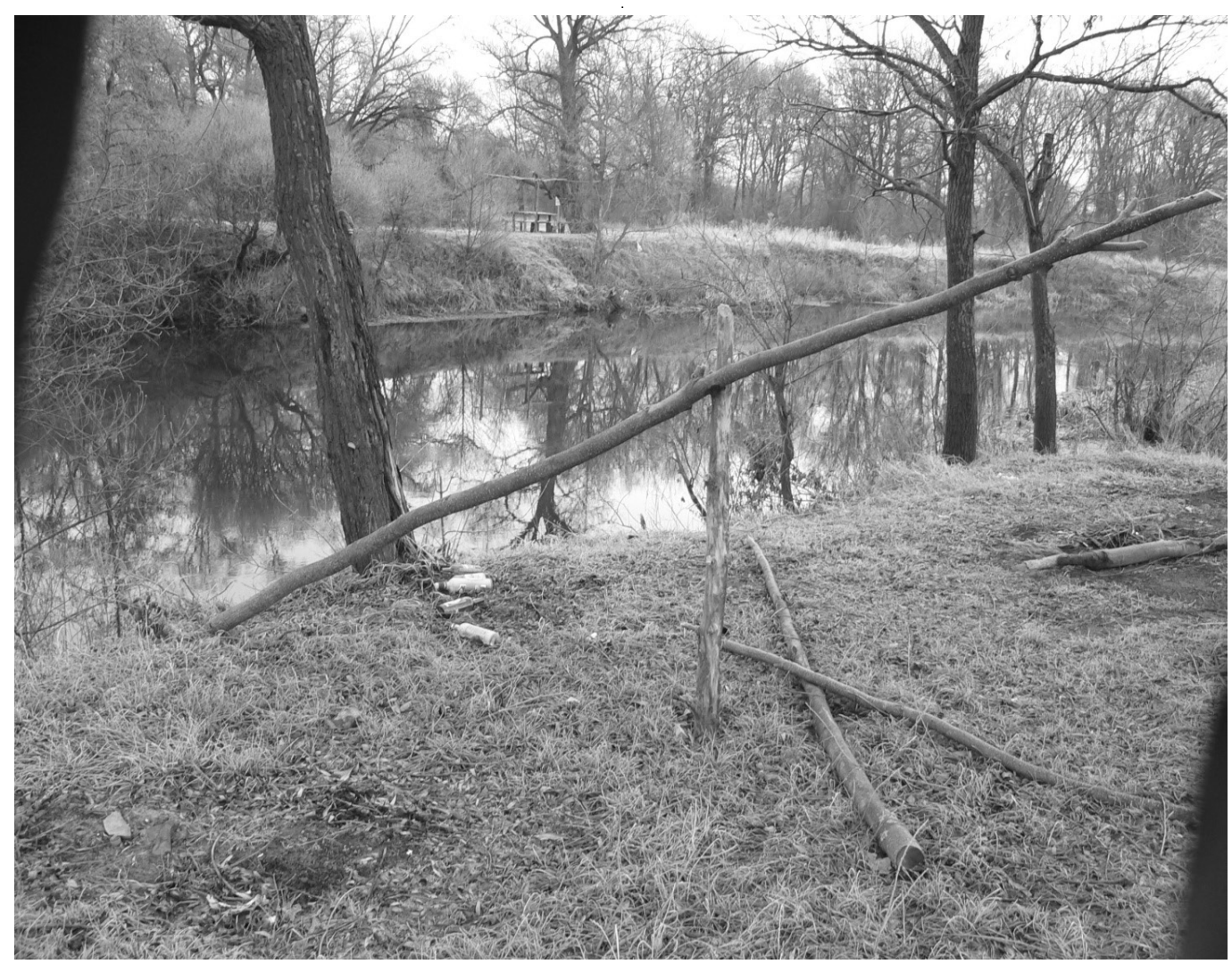

Рис. 4. Место отдыха с концентрацией бытового мусора у Плеховского моста

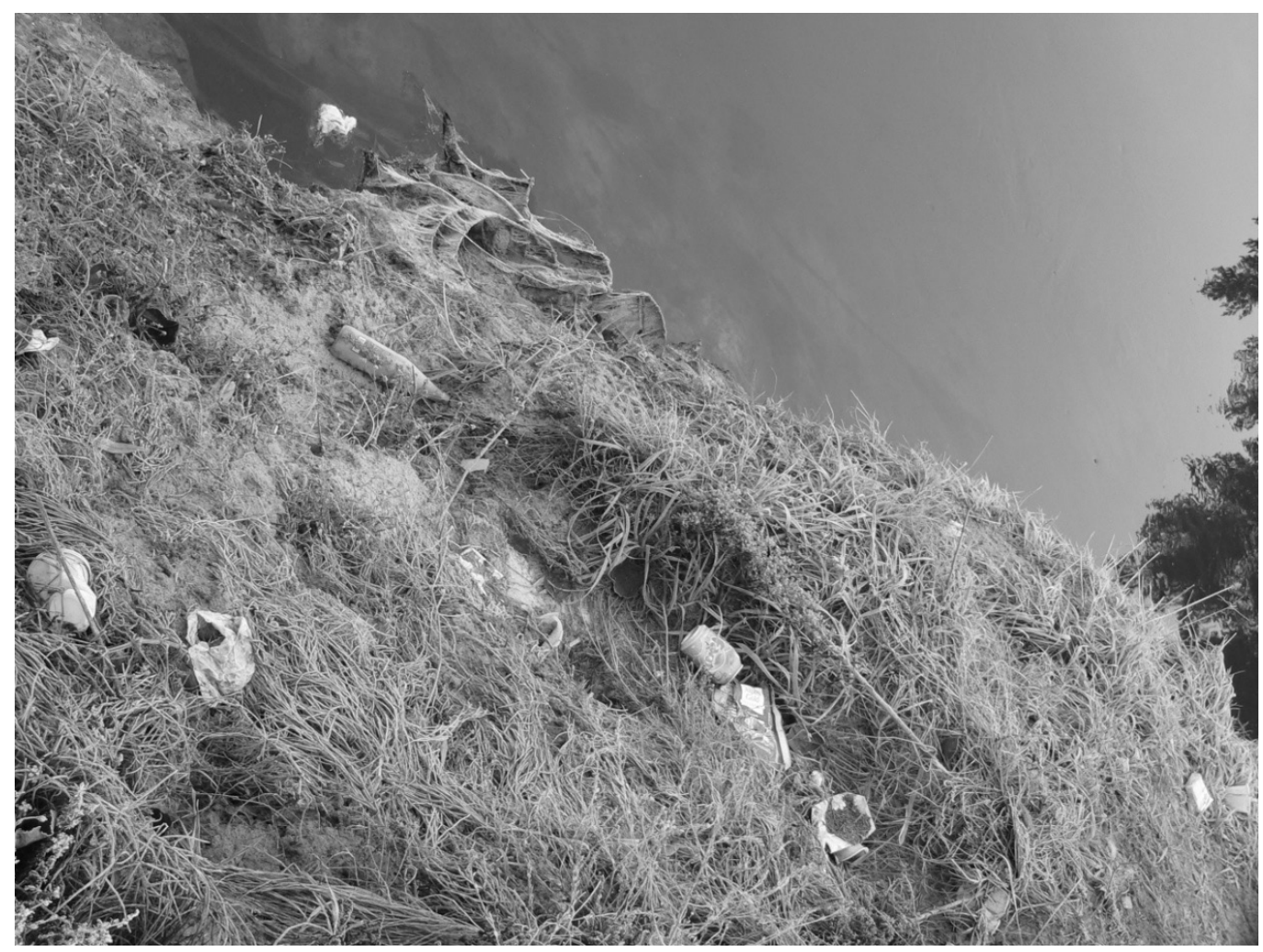

Рис. 5. Бытовой мусор на береговой линии Псла 
гах стали различные столики, скамейки, навесы вокруг которых массово концентрируется бытовой и пищевой мусор (рис. 4-5).

В связи с продолжающимся наступлением межвековой тепло-засушливой циклической фазы и невозможностью регулирования севооборота из-за полного перехода сельского хозяйства в руки мелких собственников (фермерских, а также и большей части прудовых хозяйств), улучшение питания реки с помощью лесомелиорации, столь эффективно показавшее себя в период 50-х - 80-х годов двадцатого века, даже теоретически невозможно.

Поэтому единственным решением для повышения уровня воды в реке Псёл и предотвращении быстрого сброса воды в весенний период является создание каскада переливных подпоров на месте спрямленных русел - промытых меандров. Только на территории Беловского и Суджанского районов необходимо установление таких сооружений не менее чем в девяти местах (1 подпор между с. Лошаковка и Песчаное, установка 2 подпоров у с. Песчаное, 1 подпор между с. Песчаное и Суходол, 1 подпор между с. Гирьи и Белица, 1 подпор у с. Крупец, 1 подпор у с. Спальное, 1 подпор между с. Спальное и Борки, 1 подпор у с. Борки) с условием подъема воды от 0,5 до 1 метра, с учетом того, что сегодня уровень на Псле находится от 0,5 до 0,7 метра ниже обычных меженных.

Перекрывание основных спрямленных русел будет способствовать:

1. замедлению сброса воды в период весеннего половодья и сезонных паводков;

2. к равномерному подъему уровня воды на всем протяжении реки;

3. улучшению аэрация реки в зимний период из-за непосредственного сброса воды через переливные подпоры;
4. подъему и стабилизации уровня воды в притоках, пойменных и прирусловых болотах;

5. подъему уровня воды и увеличению средней глубины, что предотвратит зарастание водной растительностью, а также даст более благоприятные условия для распространения и увеличения численности ихтиофауны, в первую очередь наиболее ценных видов: леща, судака, жереха, щуки и т.д.;

6. миграции рыб при наличии постоянного функционирования «длинных» русел, в том числе и нерестовые;

7. к исключению заиливания реки.

Целесообразно одновременно с предлагаемыми выше мероприятиями рекомендовать следующее:

- создание зимовальных ям (глубиной от 10 метров), за счет искусственного углубления русла (как пример, участок ниже моста на трассе Суджа-Плехово);

- углубление русла на протяжении до 1,5-2 км (на участке Лошаковка - Песчаное; под с. Песчаное; под с. Белица, под с. Спальное);

- облесение береговой линии Псла на всем ее протяжении и полное облесение островов у с. Песчаное (5 островов), у с. Спальное, у с. Борки, а также части береговых линий притоков Псла;

- прекращение выпаса скота по поймам как самого Псла, так и его притоков;

- ограничение доступа автотранспорта к реке;

- выведение из потенциально опасных зон животноводческих комплексов и полигонов по утилизации бытовых отходов;

- борьба со всеми видами рыбного и другого браконьерства.

Внедрение предложенных мероприятий будут способствовать восстановлению и экологической реабилитации реки Псёл.

\section{ЛИТЕРАТУРА}

1. Доклад о состоянии и охране окружающей среды на территории Курской области в 2018 году // Администрация Курской области http://adm.rkursk.ru.

2. Руководство по гидробиологическому мониторингу пресноводных экосистем / под ред. В. А. Абакумова. СПб.: Гидрометеоиздат, 1992.317 с.

(с Дмитриева Екатерина Леонидовна ( sv-dmitr@yandex.ru). 